\title{
Integrating Technologies in the New Normal: A Study of Blended Learning
}

\author{
Rahma Sakina ${ }^{1, *}$, Eva Meidi Kulsum², Aip Syaepul Uyun ${ }^{3}$ \\ ${ }^{1,2,3}$ Department of English Education, Ma'soem University, Indonesia \\ *Corresponding author email: rahmasakina@masoemuniversity.ac.id
}

\begin{abstract}
The objective of this research is to describe how the teacher integrates technologies in blended learning and to analyze students' perception and challenges in blended learning. The research was conducted in a private senior high school in Bandung and used a qualitative descriptive method. The data were collected through interview and questionnaire. The findings show that the teacher had already integrated technologies to run the process of teaching and learning in the new normal era as a replacement of a face to face learning due to Covid-19 pandemic. In the blended learning, the teacher integrated the variety of technologies in teachinglearning activities, namely zoom meeting and WhatsApp group chatting for the synchronous learning and she utilized google classroom, screencast o matic screen recorder, viva video editor, YouTube, and Quizizz the synchronous learning. The students perceived blended learning positively and determined that it is is one of the effective ways of teaching. The biggest challenge overcome by the teacher is more time needed to learn and adapt to this new situation where they must employ technology in our educational culture. For the students, the stability of internet connection also becomes major obstacle in blended learning. Apart from that, blended learning can be an option applied in the learning process in the current pandemic era.
\end{abstract}

Keywords: ICT, bleanded learning, new normal

\section{Introduction}

The advance of technologies has become indispensable necessary tools over present time, and it has influenced living and working in a new global era. This development has brought us to the new paradigm and challenge in the world of education. This challenge does not only relate to the future demands of students on their work, but also bring us to adapt with the new approach of teaching and learning in order to best prepare future generation such as in Covid-19 era (Delors, 1998). Since COVID-19 was found in Wuhan at the end of December 2019 until it spreads out the world wide and becomes a pandemic, this virus affects many aspects in society including the educational aspect 
(Rachmadtullah et al., 2020). Face-to-face learning, which is common in Indonesia, is stopped to prevent a wider spreading of COVID-19 since April 9, 2020. Since that time, all Indonesian teachers are required to conduct distance learning during the pandemic. As stated by Roblyer and Edwards (2000), distance learning is defined as the process of getting knowledge and skills through mediated information and instruction, including various technologies and other forms of learning at a distance. In the distance learning, the teacher can use a variety of technologies to support teaching and learning activities at home with no contact directly with the students and it can prevent the risk of spreading out the COVID-19 among them.

Integrating the variety of technologies in teaching-learning activities enables the teacher to use various types of instructional delivery modes (media) with the flexible time, place (Fong et al., 2010). This way can be one of the choices to answer current situation on how actually educational system has to adapt with this new normal in Covid-19 era. Currently, scholars introduced the new way of teaching which is called blended learning. Etymologically, the term blended learning comes from two words, namely blended which means mixture and learning which means learning (Lata, 2017). Thus it can be said that blended learning means learning patterns that contain elements of mixing or combining one pattern with another in learning. Alnajdi (2008) states that what is mixed in blended learning are two main elements, namely classroom learning with online learning. It aims at bridging distance and giving more flexible access in the process of learning.

The term blended learning has been defined by a lot of scholars with various focuses. Staker and Horn (2012) and Procter (2003) define blended learning as a teaching model and learning styles in which the students have controlled over time, place, and or pace. In other words, in blended learning the students have more flexibility to decide when, where, and how fast they are going learn. This is also supported by Garrison and Vaughan (2008) who stated that blended learning is a student-centered, self-paced, flexible and multi-modal approach to learning. Thus, it can be said that blended learning emphasizes the use of multi-modal delivery with the features of students' flexibility to control over time, place, and pace.

Furthermore, the most prominent definition of blended learning is the combination of online and face-to-face instruction (Graham, 2004; Rooney, 2003; Sands, 2002). This means the process of teaching contains of two activities, both face to face and online. However, the other scholars view blended learning in the different point of view. Friesen (2012) in Bryan and Volchenkova (2016) argued that blended learning means almost any combination of teaching includes technology, pedagogy and even task working. While Chew et al., (2008) stated that blended learning is the combination between education and educational technology. Thus, it is clear to see that blended learning is a new approach of teaching using any kinds of instrument which also put technology as the foundation in its instruction.

One frequent question emerging in the discussion of blended learning is about what is being blended (Graham, 2004). According to (Graham et al., 2003) there are at least three types of combinations that are most often used as a reference. The first type is the combination of different delivery modes or modalities or media. The second is the combination instructional method. The last one is the combination online and face to face instruction. In the present research, the concept of blended learning being used is the first concept which is the combination of different delivery modes or modalities or media.

Levin et al., (2013) add that blended learning combines the best of synchronous and asynchronous learning approach to meet specific educational goals. Synchronous learning approach 
is defined as live and real-time facilitated instruction that is usually scheduled (Shahabadi and Uplane, 2015). This means that learning activity is carried out by the teacher and students at the same time and it is commonly facilitated by media such videoconferencing and chat. For example, the teacher conducts synchronous e-learning through Zoom meeting or Google meet. Hrastinski (2014) adds that teachers and students conduct synchronous e-learning as more social activity which means it helps students to be more aware of themselves as parts of a community instead of isolated individuals who communicate with the computer.

On the other hand, asynchronous learning is an interactive learning activity that is not limited by time and place (Mayadas, 1997 cited in Shahabadi and Uplane, 2015). In other words, asynchronous learning emphasizes the flexibility of e-learning so the students can learn anytime and anywhere. For example, the students sign in e-learning at any time and they can download materials in forms of documents or pdf, and they can send message to teachers or peers. Furthermore, Hrastinski (2014) states that asynchronous learning is commonly supported by media such as email, Google Classroom, support work relations among teachers and students, even when the students cannot be online at the same time.

This combination between synchronous and asynchronous learning style is one example of blended learning. As blended learning views the learning activity as a continuous process that encourages the students to be independent students outside the classroom, it is considered as a better approach than the conventional face-to-face learning (Eddy et al., 2014 cited in Maarop and Embi (2016). In addition, blended learning has improved many elements in pedagogy such as access, flexibility, student engagement and participation (Alebaikan and Troudi, 2010; Gomez and Igado, 2008; Garrison and Kanuka, 2004). Those facts make blended learning becomes a current trend in education, especially in higher education (Maarop and Embi, 2016).

Several studies related to blended learning had been conducted by the other researchers such as Rachmadtullah et al., (2020), Luaran et al., (2015), and Dziuban et al., (2018). Rachmadtullah et al., (2020) investigated the effectiveness of blended learning with Moodle in an elementary school during COVID-19 pandemic. This study employed a quasi-experimental design and found that the use of blended learning with Moodle is effective and it can be used as an alternative learning media during the pandemic.

The other study related to blended learning was conducted by Luaran et al., (2015) with the aim of study is to examine student satisfaction, willingness, and stress in learning English through blended learning. The research design of this study is a quantitative study with the instruments of surveys and interview. The results showed that the levels of students' satisfaction and willingness are high and the level of students stress is low. The students view that three elements that are significant in blended learning are progress toward learning objectives, making an effective learning environment and the teachers' effective communication. When they view those three elements of a class are satisfied they evaluate the class as excellent too.

The last previous study that investigated blended learning was conducted by Dziuban et al., (2018). The study aims at examining the success and withdrawal rates of higher education students in blended learning and their perception of their learning environments. This study employed a quantitative design and the results showed that blended learning has a slight advantage when looking at the rates of students' success and withdrawal. This is different with different discipline and course.

All of the previous researches use a quantitative design while the present study employs a 
qualitative design, especially a case study whose advantage is being able to provide an in-depth description and analysis toward the issue under investigated, namely blended learning (Heigham and Croker, 2009; Malik and Hamied, 2014). Furthermore, two previous researches were conducted in other country contexts and the rest study was in Indonesian context with its focus is the utilization of Moodle application in blended learning. In this study, blended learning is conducted through various technologies which become the latest trend such as Google Classroom, power point with voice recording, video editor, YouTube, and Quizizz.

Based on the explanation above, this study attempts to contribute to teaching-learning English with ICT, especially in blended learning practice. The present study aims to describe how the teacher integrates technologies in blended learning, to analyze how the students perceive blended learning using technologies, and to explain challenges overcome by the teacher and students during blended learning. The findings of this study are expected to be one of references to design blended learning with various technologies in the new normal.

\section{Research Method}

This study employed a qualitative method by distributing questionnaires and conducting an interview session of which this research highlighted explicitly about the students' perspective of blended learning using technologies and how the teacher integrates technologies in a blended learning. This study is considered as a case study because it examines a specific phenomenon; the integration of technologies in a blended learning.

This study was carried out in a certain private senior high school in Bandung where all of the teachers have already integrated technologies to run the process of teaching and learning in the new normal situation as a replacement of a face to face learning. A teacher who teaches English was chosen as a participant of this study. She teaches in all grades of students. The students from grade XII were also chosen as participants in consideration that they are considered as the higher-level students who have longer exposure to technologies in school.

The process of investigation was started by collecting relevant data to answer the research questions. This study adapted questionnaires from Dziuban et al., (2018). It consists of 18 statements to investigate students' perceptions of blended learning and challenges they had during teaching and learning process in the new normal situation. 15 statements of the questionnaire are in the form of close-ended questionnaire following the Likert Scale and the rest three statements are in the form of open-ended questionnaire. The 9 of 15 close-ended statements are considered as a way to find out how students perceive blended learning related to the way how the teacher implemented it in the classroom, including organizing the course (item 1), explaining course requirements, grading criteria, and expectations (item 2), communicating ideas and/or information (item 3), showing respect and concern for students (item 4), stimulating interest in the course (item 5), creating an environment that helps students learn (item 6), giving useful feedback on course performance (item 7), helping students achieve course objectives (item 8), the overall effectiveness of the instructor in the course (item 9). While the rest 6 open-ended statements referred to the way how the teacher integrated technologies using some applications like Zoom (item 10), Google Classroom (item 11), PPT (item 12), YouTube (item 13), WhatsApp group (item 14), and Quizizz (item 15). On the other hands, the 3 statements of open-ended questionnaire asked about students' preference (item 16), challenges (item 17), and suggestions (item 18). This questionnaire is 
appropriate with the problem being analyzed in this study because it can investigate students' perception about blended learning implemented by the teacher in more detailed.

As a gold standard of qualitative research, an interview session was conducted to increase the feasibility of this study and to seek an important source of information to identify the underlying reasons. In this session, 6 students were selected purposively to be interviewed. To develop this instrument, it was referred to the statements revealed in the questionnaire about the implementation of blended learning and challenges that they had during teaching and learning process. While to find out how the teacher integrates technology, interview was performed to seek the information being investigated.

The data from questionnaire were analyzed qualitatively by calculating the percentages to infer the data findings. Meanwhile, the data from interview were analyzed to corroborate and confirm the data from questionnaires. In supporting the finding from questionnaires, the data from the interview was cited in the analysis following Creswell's suggestion to use the wording from participant to give a detailed descriptive portrait (Creswell, 2013).

\section{Findings and Discussions}

This section describes the results of study and discussions which are taken from transcription of interview and questionnaire. The findings are intended to answer the purposes of study which include analyzing how the teacher integrated technologies in blended learning, how the students perceive blended learning using technologies, and what challenges overcome by the teacher and students during blended learning.

In response to the first research objective, the data were analyzed based on the framework of Levin et al., (2013) who emphasize that blended learning combines the best of synchronous and asynchronous learning. In terms of synchronous learning, the teacher employed two applications including Zoom meeting and WhatsApp group chatting. In the asynchronous learning, the teacher used some applications and platforms, namely Google Classroom, screencast o matic screen recorder, viva video editor, YouTube, and Quizizz.

To make the explanation easy to comprehend, the data were coded into some stages which are preparation, introduction, teaching process, discussion, and assessment. In the preparation stage, the teacher prepared the platform of Google Classroom to organize all information related to her class such as the syllabus, the materials, the assignment, and the students' scores. This platform was employed since it is easy to use and beneficial to organize everything related to teaching materials, students' tasks and scores very well so that the teacher can recheck everything easily. The advantages of Google Classroom in terms of its ease of use and usefulness in learning activity is supported by Albashtawi and Albataineh (2020) who found that the students showed positive attitude toward the use of Google Classroom because of its ease of use and usefulness. Inoue and Pengnate (2018) added that the students were highly satisfied with utilizing Google Classroom to submit online homework. From these findings, Google Classroom is useful to manage all information and documents related to teaching-learning activities. Furthermore, in the Google Classroom the students can communicate easily with the teacher and their classmates in comment column of every post.

In the preparation stage, the teacher also prepared the teaching materials in forms of power point and video explanation. After she made the power point, she recorded her explanation of materials 
by using a screen recorder application called screencast o matic and then she edited it by a video editor apps called viva video. The reason why the participant employed some applications to create the teaching materials is because using only one resource to learn (one teaching media) is not effective, especially when the materials are hard enough. Therefore, the use of various media is used to help the students understand the materials more easily. It is supported by Guichon and McLornan's (2008) results of study which indicated that comprehension is improved when learners are exposed to a material in several modalities. The use of multimodal in teaching is really useful for students' comprehension, especially in this new normal where the teacher and students carry out teaching-learning activities at home.

The next stage is introduction in which the teacher introduced all necessary information about the class to the students. In the first meeting, the teacher explained the syllabus containing the learning objectives, the topics, the source, the learning activities, and the evaluation. In this meeting, the participant used Zoom meeting apps so she can communicate directly with the students. In other words, this stage can be called synchronous e-learning. As stated by Shahabadi and Uplane (2015), synchronous e-learning approach is defined as live and real-time facilitated instruction that is usually scheduled. The synchronous e-learning also has a social function which means it makes the students more aware that they are parts of a community rather than isolated individuals who communicate with the (Hrastinski, 2014). In this new normal, communicating with friends or teacher through video calling or teleconferencing is useful to avoid them from loneliness and keep the mental health. The teacher did not use this application in every meeting because of the limited internet data of students and the unstable internet connection in various areas. Therefore, the use of Zoom meeting in every meeting will not be effective.

In the following meetings, the learning process was carried out through Google Classroom, YouTube, and WhatsApp group. After the teacher prepared the video materials, she uploaded it on YouTube and copied its link on Google Classroom. The reason why she uploaded the materials on YouTube is because of the flexibility of students to watch the materials anywhere and anytime. In addition, when the students did not really understand it, they can replay the video. The flexibility of students in learning is also emphasized in blended learning. As stated by Alebaikan and Troudi (2010), blended learning provides flexibility to students to control over time and place in learning. After uploaded the video on YouTube, the teacher then informed the students about the materials and asked them to check the Google Classroom and learn the materials independently. In this process, the learning activities were done asynchronously in which the students learned the materials provided in the Google Classroom independently. As stated by Hrastinski (2014) asynchronous learning is commonly supported by media such as email and Google Classroom.

After the students read and watched the materials, in several meetings the teacher discussed some examples of questions on WhatsApp group and many students participated in the discussion. In the discussion process, learning activity was carried out in synchronous learning. As stated by Shahabadi and Uplane (2015), synchronous learning means that learning activity is carried out by the teacher and students at the same time and it is commonly facilitated by media such videoconferencing and chat. The discussion session is useful to help the students to more comprehend the materials.

In the assessment stage, the teacher employed a platform called Quizizz in which she created a quiz containing fifteen multiple-choice questions and distributed them to students through Google 
Classroom. The teacher used this platform because it is really useful to help her to check the students' answers automatically and their scores are also saved automatically. In addition, this platform creates the quiz in a semi-game form with the music and pictures, so the students do the task happily. The use of technology in teaching-learning process makes it more exciting. As stated by Cahyani (2012) and Altun (2015), the use of ICT makes language teaching exciting and makes the students more motivated.

The other interesting feature of Quizizz flatform is the duration of answering the questions can be set by the participant, so the students cannot cheat to their classmates during the quiz. As the assessment process was not carried out at the same time among the students, this process is called asynchronous. As stated by Mayadas (1997), asynchronous learning is an interactive learning activity that is not limited by time and place. In other words, asynchronous learning emphasizes the flexibility of e-learning so the students can learn anytime and anywhere.

To seek the information about students' perceptions of blended learning, the questionnaire adapted from Dziuban et al., (2018) was revealed. The questionnaire aimed to figure out the students' perceptions of blended learning that is implemented in the new normal era. Based on the result from questionnaire, most of the students have a positive respond to the implementation of blended learning including the way how the teacher integrates technologies using some applications. For more information about the result of data analysis of questionnaire, the mean score of each statement is tabulated in Table 1.

Table 1. Mean Score of the Implementation of Blended Learning

\begin{tabular}{cc}
\hline Item & $\begin{array}{c}\text { Mean } \\
\text { Score }\end{array}$ \\
\hline 1 & 4.13 \\
2 & 4.1 \\
3 & 4.05 \\
4 & 4.45 \\
5 & 4.02 \\
6 & 4.08 \\
7 & 3.97 \\
8 & 4.26 \\
9 & 3.84 \\
\hline
\end{tabular}

Based on the Table 1 there are seven statements whose means scores are above 4 while three other statements are under 4. Based on the Likert Scale's interpretation, they perceived the blended learning positively. Item 4 got the highest mean score. It refers to the teacher's respect and concern for students. This is considered as a very important aspect. According to Thompson (2018), in order to foster positive teacher-student relations and improve student discipline teachers should seek to show respect to students. Thus, respect has positive effects on teacher-student behavior then the absence of respect may be deemed to be a contributor to negative student-teacher relationships and negative attitudes of students towards school and school authorities, although the negative attitudes 
of students towards school and school authorities result from a variety of factors. In addition, when teacher showed respect to the students, it will result students' comfort with learning environment. This is also in line with Idu and Ojedapo (2011) who noted that if teachers ignore students' problems and complaints whether academic or otherwise this prepares ground for indiscipline to the students. This is also implied in the interview session, students assumed that teacher have made them feel secure and satisfied in this new online learning environment. Therefore, in this case, teacher has successfully created a comfort learning environment for students which results a positive perception.

The next highest scores are item 8,1 , and 2 . These items related to the teacher's help in achieving the objective of the course, organizing the course, and explaining the course requirements including grading criteria, and expectations. According to the students' explanation in the interview session, teacher gave a very clear instruction in organizing the course; however, online learning does not feel too much different with a face to face learning. The teacher also helped students to achieve the course objective by providing great various method of teaching starting from making YouTube content to designing assessment tools using applications that stimulate students' achievement. In other words, it is clearly indicated that the teacher supported students' academic achievement. Additionally, Sharma (2016) argued when students view their teacher as supportive, they showed a more positive academic self-concept and greater expectancies for success. Perceiving the teacher as supportive is also related positively to a desire to comply with classroom rules.

Table 2. Mean Score of Technology Integration

\begin{tabular}{cc}
\hline Item & $\begin{array}{c}\text { Mean } \\
\text { Score }\end{array}$ \\
\hline 10 & 3.73 \\
11 & 4.13 \\
12 & 4.08 \\
13 & 4.05 \\
14 & 3.84 \\
15 & 4.03 \\
\hline
\end{tabular}

Besides, based on the result from questionnaire, the teacher also showed a great detail of communicating ideas and/or information, giving useful feedback on the course performance, creating an environment that helps students learn, and stimulating interest in the course. It can be seen clearly when student who was interviewed stated that since the first meeting of the course, teacher always informs every single information related to the course on WhatsApp group or other application such as Zoom or Google Classroom, if it is necessary, including giving useful feedback on the students 'performance. Students also enjoy the learning activities that have been designed by the teacher because it provides various kinds of activities that students can comprehend without feeling bored. Therefore, it can be concluded that teacher has already been successful to stimulate students' interest in following the course and creates a supportive learning environment that helps students learn best. Dealing with this case, the students need to have interest. Students' interest in learning English is important because without interest the students will not be motivated in learning. 
In addition, interest can affect the quality of students' learning achievement in a certain subject. The next finding is associated with the way how the teacher integrates technologies using some application. Overall mean score of this point is 3.98 which indicated that more than $75 \%$ students have a good perception toward technology integration of blended learning in the new normal era. For more information about it, see Table 2.

The Table 2 showed mean score of each item related to the use of technology in implementing blended learning. Blended learning cannot be separated from technology because technology has made it possible to be implemented. However, seeking information about it is necessary to be conducted. Based on the table, Google Classroom got the highest positive respond from the students; it is item 11. Then it was followed by PowerPoint Presentation Video, YouTube content, and Quizizz. While Zoom and WhatsApp group got the lowest mean score but it does not mean that they are not effective to support the blended learning. The mean scores of them are above 3.5 which mean that more than $70 \%$ students perceived them positively; the application of each platform or application has been explained previously. Conforming to this discussion, Yusuf (2005) revealed that technology has a potential to motivate and engage students in learning. By their very nature, technology is a tool that enables students to encourage and support learning independently. Moreover in this new normal era, technology plays an important role to support teaching and learning process for both teacher and students. Teacher should pay more attention to design material, one of the very possible ways to do is integrating technology in order to attract students' interest and increase their achievement. In line with that, Kaplan and Owings (2001) affirmed that flexibility, creativity, and adaptability are factors that must be considered by the teacher to increase the students 'achievement. The teacher who is a participant in this research, based on the students answered in the interview session, have already integrated technologies very well. They like how the way she organized the course using technologies. For example, when the assessment system is conducted using Quizizz. One of the students said that it is so challenging yet interesting. Examination does not feel that terrify compared to face to face exam. In relation with this, Zhao (2019) also confirmed in his study that students report that Quizizz brings positive impact on their learning experiences.

Paying attention to the challenges which were faced by both teachers and students using blended learning, the researcher interviewed both English teachers and student. To support the data from interview, the questionnaire was also conducted.

Referring to the data from the interview, it was found that obviously behind its benefits, both teacher and students still found some obstacles in implementing blended learning. The teacher informed that she need more time to learn more and adapt to this new situation where they must employ technology in our educational culture. She said that even she can operate some applications or media platform, yet still she need to comprehend it. It is in line with current research published by Sari (2020) which is said that Covid-19 came unplanned, so teachers and students without any preparation are forced to adapt to this new habit. One measure is to use blended learning strategy, but teachers need more time to get used to it. Somehow, it cannot be denied that the advances of technologies have become indispensable necessary tools over present time, and it has influenced living and working in our new global era (Costa and Liebman, 1995). So we need to get in used to it. 
Another obstacle found is about the capacity of the teacher to operate the media based on technology. It is yes, using technology will help us to be effectively to control learning teaching process, just like what Cook (2015) suggested. However on the other hand, it is also essential that we have to pay more attention to the reality. Covid-19 comes suddenly, and adapting new situation and new knowledge on operating any kinds of application and media virtual platform such as Zoom, Google meet, or teleconference is not easy to do in short time. Teacher argued that using blended learning between synchronous and asynchronous is somehow considered difficult by the teachers. They must prepare the materials whether it is in power point, or you tube, and after that they must edit it and upload it, then go to the instruction. They categorize this as complicated. So this becomes another challenge in blended learning. This does not surprise us, because any previous research had revealed the same conditions Koesnandar in Sari (2003) reported that blended learning gives more challenges to the teacher because they have to learn and understand the use of the latest technologies, so that teachers can use them appropriately and efficiently.

Furthermore, other challenges also arise from the attitude of students during learning processes. According to the interview data, teachers are often disappointed by students' behavior that does not have much respect and attention during blended learning process. Many of them rarely do their assignments because blended learning is considered informal, unlike face to face learning. It is in line with Pardede (2019) he found that many teachers stated various advantages they can obtain through online platform used. They also realized that the online platform offers various interesting media like pictures and videos that helped them study interestingly. However, they still valued faceto-face instruction higher due to the realistic interactions.

Referring to the students' point of view, this new habit has become another distinctive story for them. There are many new things that need to be adapted so that they can continue their activities as usual. One of the new things is blended learning model in their school. Various response was recorded and many of them argued that blended learning is one of the effective ways of teaching in today situation, yet not a few students also argue this hard. They informed that the most challenging aspect in blended learning synchronous and asynchronous is on the stability of internet connection. Majority of them argued that they frequently got an obstacle related to this aspect. This data remains us on another view of Indonesian educational system. It must be aware that we still have many troubles and challenges. This is also informed in Syae (2018) he said learning based on technology in our education still did not meet the needs of Indonesian society. The lacks of infrastructures becomes a big problems in underdeveloped countries such as Indonesia. Besides, Human resources of educators having comprehensive understanding and ability on this topic is also still limited.

The last, another challenge presented by the students was regarding the effectiveness of blended learning when it comes to use it for discussion, they conveyed that media application and technology is not effective as applying face-to-face class meeting. The access given is not as flexible as when we come to school directly. We can discuss, ask the teacher more effectively. This is contrast with Carter (2013) in Syae (2019) who stated that the flexibility and accessibility of elearning, including the various online learning resources exposure and the convenience of self-pacing and regulating their study increase students' enthusiasm. It is naive to say that there are no challenges on one strategy or model applied. However, the existing challenges will be used as future evaluation for improvement. 


\section{Conclusion}

This research has focused on blended learning in term of synchronous and asynchronous learning. It is one of the many learning strategies chosen during Covid-19 pandemic. Integrating the variety of technologies in teaching-learning activities enables the teachers to use various types of instructional delivery modes with the flexible time and place. The findings show that the teacher employed different types of applications and platforms in the blending learning, namely Zoom meeting and WhatsApp group chat for the synchronous learning and she utilized Google Classroom, screencast o matic screen recorder, viva video editor, YouTube, and Quizizz for asynchronous learning. The research also found that students perceived blended learning positively and argued that it is one of the effective ways of teaching. The biggest challenge found that teacher need more time to learn more and adapt to this new situation where they must employ technology in our educational culture. Other, the stability of internet connection also becomes major factors in their own challenges.

\section{References}

Albashtawi, A., and AlBataineh, K. (2020). The Effectiveness of google classroom among EFL students. International Journal of Emerging Technologies in Learning (IJET), 15(11), 78-88.

Alebaikan, R., and Troudi, S. (2010). Blended learning in Saudi universities: challenges and perspectives. ALT-J Research in Learning Technology, 18(1), 1-12.

Alnajdi, S. M. (2008). Hybrid Learning in Higher Education: Engagement Strategies. College \& University Media Review, 14(1), 145-158.

Altun, M. (2015). The Integration of Technology into Foreign Language Teaching. International Journal on New Trends in Education and Their Implications (IJONTE), 6(1), 20-27.

Bryan, A., and Volchenkova, K. N. (2016). Blended Learning: Definition, Models, Implications for Higher Education. Bulletin of the South Ural State University Series “Education. Education Sciences," 8(2), 24-30.

Cahyani, H. (2012). Teacher's Attitude and Technology Use in Indonesian EFL Classrooms. TEFLIN Journal, 23(2), 130-148.

Chew, E., Jones, N., and Turner, D. (2008). The Marriage of Rousseau and Blended Learning: An Investigation of 3 Higher Educational Institutions' Praxis, Advances in Web-Based Learning, LNCS. Springer, Heidelberg, 4834, 641--652.

Creswell, J. W. (2013). Research Design: Qualitative, Quantitative, and Mixed Methods Approaches. In Research design Qualitative quantitative and mixed methods approaches, 203-224.

Delors, J. (1998). Education for the twenty-first century: issues and prospects. UNESCO.

Dziuban, C., Graham, C. R., Moskal, P. D., Norberg, A., and Sicilia, N. (2018). Blended learning: the new 
normal and emerging technologies. International Journal of Educational Technology in Higher Education, 15(1), 1-16.

Fong, J., Wang, F. L., and Kwan, R. C. (2010). Handbook of Research on Hybrid Learning Models: Advanced Tools, Technologies and Applications. Information Science Reference.

Garrison, D., and Vaughan, N., D. (2008). Blended Learning in Higher Education: Framework, Principles and Guidelines. Jossey-Bass.

Garrison, D. R., and Kanuka, H. (2004). Blended learning: Uncovering its transformative potential in higher education. He Internet and Higher Education, 7(2), 95-105.

Gomez, J., and Igado, M. (2008). Blended learning: The key to success in a training company. International Journal of Instructional Technology and Distance Learning, 5(8), 1-12.

Graham, C. R. (2004). Blending Learning System, Definition, Current Trends, andFuture Direction. Brigham Young University.

Graham, C. R., Allen, S., and Ure, D. (n.d.). Benefits and challenges of blended learning environments (M. Khosrow). Idea Group Inc.

Guichon, N., and McLornan, S. (2008). The effects of multimodality on L2 learners: Implications for CAAL resource design. Science Direct, 36(1), 85-93.

Heigham, J., and Croker, R. S. (2009). Qualitative Research in Applied Linguistics: A Practical Introduction. Palgrave Macmillan.

Hrastinski, S. (2014). Asynchronous and Synchronous E-Learning. January 2008.

Idu, A. P., and Ojedapo, D. O. (2011). Indiscipline in secondary schools: A cry to all stakeholders in education. Journal of Educational and Social Research, 81(2), 25-36.

Inoue, M., and Pengnate, W. (2018). Belief in foreign language learning and satisfaction with using Google classroom to submit online homework of undergraduate students. 5th International Conference on Business and Industrial Research (ICBIR), 618-621.

Kaplan, L. S., and Owings, W. A. (2001). Teacher Quality and Student Achievement: Recommendations for Principals. NASSP Bulletin.

Lata, K. D. (2017). Blending Learning: An Inovative Approach. University of Lucknown. Uttar Pradese.

Levin, S., Whitsett, D., and Wood, G. (2013). Teaching MSW social work practice in a blended online learning environment. Journal of Teaching in Social Work, 33, 408-420.

Maarop, A. H., and Embi, M. A. (2016). Implementation of Blended Learning in Higher Learning Institutions: A Review of Literature. International Education Studies, 9(3), 41-59. 
Malik, R. S., and Hamied, F. A. (2014). Research Method: A Guide for First Time Researchers. UPI Press.

Mayadas, F. (1997). Asynchronous Learning Networks: A Sloan Foundation Perspective. Journal of Asynchronous Learning Networks, 1(1), 1-16.

Procter C.T. (2003). Blended Learning in Practice. www.ece.salford.ac.uk/proceedings/ papers/cp_03.rtf

Rachmadtullah, R., Rasmitadila, R., Humaira, M. A., Aliyyah, R. R., and Samsudin, A. (2020). Use of Blended Learning with Moodle: Study Effectiveness in Elementary School Teacher Education Students during The COVID-19 pandemic Use of Blended Learning with Moodle: Study Effectiveness in Elementary School Teacher Education Students during The COV. May.

Roblyer, M. D., and Edwards, J. (2000). Integrating educational technology into teaching (2nd ed.). Merrill.

Rooney, J. E. (2003). Blending learning opportunities to enhance educational programming and meetings. 5 , $26-32$.

Sands, P. (2002). Inside outside, upside downside: Strategies for connecting online and face-to-face instruction in hybrid courses. 6.

Shahabadi, M. M., and Uplane, M. (2015). Synchronous and Asynchronous e-learning Styles and Academic Performance of e-learners. Procedia - Social and Behavioral Sciences, 176, 129-138.

Sharma, G. (2016). Teacher Support as Determinant of Academic Achievement. Journal of Educational Research, 2(7), 1-9.

Staker, H., and Horn, M. B. (2012). Classifying K-12 Blended Learning. Innosight Institute, May, 22.

Thompson, C. S. (2018). The Construct of 'Respect' in Teacher-Student Relationships: Exploring Dimensions of Ethics of Care and Sustainable Development. Journal of Leadership Education, 17(3), 42-60.

Yusuf, M. . (2005). Information and communication education: Analyzing the Nigerian national policy for information technology. International Education Journal, 6(3), 316-321.

Zhao. (2019). Using Quizizz to Integrate Fun Multiplayer Activity in the Accounting Classroom. International Journal of Higher Education, 8(1), 38-43. 